\title{
HAMA PENTING TANAMAN UBI JALAR (Ipomea batatas L.(Lamb)) DI KABUPATEN MINAHASA, MINAHASA UTARA, DAN KOTA TOMOHON
}

\author{
IMPORTANT PEST OF SWEET POTATOES (Ipomea batatas L.(Lamb)) IN MINAHASA \\ REGENCY, NORTH MINAHASA, AND TOMOHON CITY
}

\author{
Odi R. Pinontoan, Maxi Lengkong dan Henny V.G. Makal*) \\ *Dosen Jurusan Hama dan Penyakit Tumbuhan, Fakultas Pertanian Unsrat, Manado
}

\begin{abstract}
The research aimed to identify important pests which attack sweet potato in the field. Field and laboratory research were conducted. The field research was carried out in sweet potato cropping areas in Minahasa Regency, North Minahasa regency and Tomohon. The laboratory research was conducted in plant pests and disease laboratory, Faculty of Agriculture Sam Ratulangi University Manado to idedntify the important pest species which were found on sweet potato plants. The duration of the study was four months starting from December 2010 until March 2011. Survey method was applied with purposive random sampling. The research was used 4 period of plant growth namely 1 month, 2 months, 3 months, and 4-5 months after planting. The result showed that there were five orders identified, attacking sweet potato since the age of 1-4 months in Minahasa regency, Tomohon and North Minahasa regency. The five orders were Orthoptera, Hemiptera, Homoptera, Lepidoptera, and Coleoptera. The damage on the leaves were caused by pests coreidae, Cicadelidae, Spodoptera sp (Noctuidae), Valanga sp (Acrididae), and Oxya sp. (Acrididae), whereas on the stem was Omphisa sp (Pyralidae). Damage on the tuber was caused by Gryllotalpa sp (Gryllotalpidae), Cylas formicarius (Curculionidae) and Oryctes sp (Dynastidae).
\end{abstract}

Key words : Important Pest Plant Sweet Potatoes, Ipomea batatas $L$.

\section{ABSTRAK}

Penelitian bertujuan untuk mengetahui jenis-jenis hama dan penyakit penting yang menyerang tanaman ubi jalar di lapang. Penelitian dilaksanakan pada dua tempat yaitu : 1) Dilapang areal pertanaman ubi jalar Di kabupaten MInahasa, Kabupaten Minahasa Utara dan Kota Tomohon, dan 2) Di laboratorium Minat Hama dan penyakit Tumbuhan, Program studi Agroekoteknologi, Fakultas Pertanian Unsrat Manado untuk melakukan tahapan identifikasi jenis-jenis hama penting yang ditemukan pada tanaman ubi jalar. Lamanya penelitian diperkirakan selama 4 bulan sejak bulan Desember 2010 sampai Maret 2011. Penelitian menggunakan metoda survey dengan pengambilan data atau sampel secara purposive sampling (pengambilan sampel secara sengaja). Kriteria tahapan perkembangan umur tanaman ubi jalar yang diperlukan dalam penelitian ini adalah : umur 1 bulan sesudah tanam, umur 2 bulan sesudah tanaman, umur 3 bulan sesudah tanaman dan umur 4-5 bulan sesudah tanaman (saat panen). Jenis-jenis hama yang menyerang tanaman ubi jalar (I. batatas L.) sejak berumur 1-4 bulan sesudah tanaman di wilayah kabupaten Minahasa, Kota Tomohon dan Kabupaten Minahasa Utara terdiri dari 5 ordo yaitu ordo Orthoptera, Hemiptera, Homoptera, Lepidoptera, dan Coleoptera. Kerusakan yang ditimbulkan pada bagian daun diserang oleh hama coreidae, Cicadelidae, Spodoptera sp (Noctuidae), Valanga sp (Acrididae), dan Oxya sp. (Acrididae); pada bagian batang adalah Omphisa sp (Pyralidae); dan pada bagian umbi adalah Gryllotalpa sp (Gryllotalpidae), Cylas formicarius (Curculionidae) dan Oryctes sp (Dynastidae).

Kata Kunci : Hama penting tanaman ubi jalar, Ipomea batatas $L$. 


\section{PENDAHULUAN}

Ubi jalar (Ipomea batatas (L.) Lamb) merupakan tanaman sebagai sumber karbohidrat, vitamin $A, C$ dan Mineral yang sangat bermanfaat bagi kesehatan manusia. Selain sebagai sumber bahan pangan, ubi jalar juga merupakan sumber bahan baku industri dan pakan ternak. Luas lahan dan panen ubi jalar di Indonesia diperkirakan sekitar $230.000 \mathrm{Ha}$ dengan produktifitas sekitar 10 ton/Ha (Sarwono, 2011). Sedangkan dengan teknologi maju, melalui penggunaan varitas unggul, ubi jalar dapat menghasilkan lebih dari 30 ton umbi basah/Ha (Anonim, 2009; Rukmana, 1997; Duryatmo, 2010).

Sulawesi Utara umumnya memiliki lahan yang baik untuk pengembangan tanaman ubi jalar seperti Kabupaten Minut, Kota Tomohon, kabupaten Minahasa, Sangihe, Talaud, dan Bolaang Mongondow. Prospek pengembangan tanaman ini sebagai sumber makanan alternatif penganti beras bagi masyarakat Sulawesi Utara begitu terbuka lebar mengingat manfaat tanaman ubi jalar cukup baik kandungan gizinya.

Kalshoven (1981) menyatakan bahwa terdapat beberapa jenis hama penting yang menyerang Tanaman ubi jalar yaitu perusak daun adalah ulat Agrius sp., Heliothis armigera, Spodoptera litura, Tabidia sp. dan kumbang Aspidomorpha sp. Perusak Umbi adalah kumbang Cylas formicarius dan kumbang Leucopholis sp dan ulat Omphisa sp. (Anonim, 2009, 2010, Pracaya, 1993).

Saat ini dilaporkan bahwa pertumbuhan dan perkembangan tanaman ubi jalar di Sulawesi Utara secara Khusus di wilayah Kota Tomohon telah diserang oleh beberapa organisme penganggu tanaman terutama serangga hama dan penyakit tanaman. Tetapi upaya berupa pendekatan pengendalian belum banyak dilakukan melalui penelitian-penelitian yang dapat menunjang penerapan pengendalian menjadi lebih baik, terencana dan teraplikasi dan terevaluasi.

Berdasarkan beberapa aspek penting sebagai latar belakang penting dan bermanfaatnya tanaman ubi jalar bagi kehidupan manusia maka diperlukan tindakan pengendalian untuk menunjang data dasar dari penerapan pengendalian hama dan penyakit tanaman ubi jalar seperti pengamatan jenis-jenis hama penting selama perkembangan tanaman ubi jalar di lapang

Kelimpahan populasi serangga pada suatu habitat ditentukan oleh adanya keanekaragaman dan kelimpahan sumber pakan maupun sumber daya lain yang tersedia pada habitat tersebut. Keadaan pakan yang berfluktuasi secara musiman akan menjadi faktor pembatas bagi keberadaan populasi hewan di suatu tempat oleh adanya kompetisi antar individu.

Hama memiliki dua pengertian, secara luas hama berarti organisme yang dapat mengurangi mutu, ketersediaan, dan jumlah sumber daya tanaman bagi kepentingan manusia. Secara sempit hama berarti semua binatang yang dalam aktivitas hidupnya memakan tanaman yang dibudidayakan sehingga menimbulkan kerugian yang berarti (Anonim, 2009).

Kalshoven (1981) dan Pracaya (1993) menyatakan bahwa terdapat beberapa jenis hama penting yang menyerang tanaman ubi jalar yaitu : 1) Perusak daun adalah ulat Agrius sp., Heliothis armigera, Spodoptera litura, Tabidia sp dan kumbang Aspidomorpha sp., 2) Perusak batang, akar dan Umbi adalah kumbang Cylas formicarius, kumbang Leucopholis sp dan ulat Omphisa sp. Serta hama tikus yaitu Rattus spp.

Pada umumnya ada beberapa ordo serangga yang berperan sebagai hama dan dapat menyerang tanaman ubi jalar, menurut Rodesa (2008) dan Pracaya (1993), diantaranya:

\section{Ordo Orthoptera (belalang)}

Sebagian anggotanya dikenal sebagai pemakan tumbuhan, namun ada beberapa di antaranya yang berperan sebagai predator pada serangga lain. Anggota dari ordo ini umumnya memilki sayap dua pasang. Sayap depan lebih sempit daripada sayap belakang dengan vena-vena menebal/mengeras dan disebut tegmina. Sayap belakang membranus dan melebar dengan venavena yang teratur. Pada waktu istirahat sayap belakang melipat di bawah sayap depan. Tipe alat mulutnya adalah penggigit dan penguyah yang memiliki bagian-bagian labrum, sepasang 
mandibula, sepasang maxilla dengan masingmasing terdapat palpus maxillaris, dan labium dengan palpus labialis. Bentuk perkembangannya adalah metamorfose sederhana (paurometabola) dengan perkembangan melalui tiga stadia yaitu telur- nimfa -dewasa (imago). Bentuk nimfa dan dewasa terutama dibedakan pada bentuk dan ukuran sayap serta ukuran tubuhnya.

\section{Ordo Hemiptera (kepik/ kepinding)}

Ordo ini memiliki anggota yang sangat besar serta sebagian besar anggotanya bertindak sebagai pemakan tumbuhan (baik nimfa maupun imago). Namun beberapa di antaranya ada yang bersifat predator yang mengisap cairan tubuh serangga lain. Umumnya memiliki sayap dua pasang (beberapa spesies ada yang tidak bersayap). Sayap depan menebal pada bagian pangkal (basal) dan pada bagian ujung membranus. Bentuk sayap tersebut disebut Hemelytra. Sayap belakang membranus dan sedikit lebih pendek daripada sayap depan. Pada bagian kepala dijumpai adanya sepasang antene, mata facet dan occeli. Tipe alat mulut pencucuk pengisap yang terdiri atas moncong (rostum) dan dilengkapi dengan alat pencucuk dan pengisap berupa stylet. Pada ordo Hemiptera, rostum tersebut muncul pada bagian anterior kepala (bagian ujung). Rostum tersebut beruas-ruas memanjang yang membungkus stylet. Pada alat mulut ini terbentuk dua saluran, yakni saluran makanan dan saluran ludah. Metamorfose bertipe sederhana (paurometabola) yang dalam perkembangannya melalui stadia : telur-nimfa-dewasa. Bentuk nimfa memiliki sayap yang belum sempurna dan ukuran tubuh lebih kecil dari dewasanya.

\section{Ordo Homoptera (wereng dan kutu)}

Anggota ordo Homoptera memiliki morfologi yang mirip dengan ordo Hemiptera. Perbedaan pokok antara keduanya antara lain terletak pada morfologi sayap depan dan tempat pemunculan rostumnya. Sayap depan anggota ordo Homoptera memiliki tekstur yang homogen, bisa keras semua atau membranus semua, sedang sayap belakang bersifat membranus. Alat mulut juga bertipe pencucuk pengisap dan rostumnya muncul dari bagian posterior kepala. Alat-alat tambahan baik pada kepala maupun thorax umumnya sama dengan anggota ordo Hemiptera. Tipe metamorfose sederhana (paurometabola) yang perkembangannya melalui stadia : telur-nimfadewasa. Baik nimfa maupun dewasa umumnya dapat bertindak sebagai hama tanaman.

\section{Ordo Coleoptera (kumbang)}

Anggota-anggotanya ada yang bertindak sebagai hama tanaman, namun ada juga yang bertindak sebagai predator (pemangsa) bagi serangga lain. Sayap terdiri dari dua pasang. Sayap depan mengeras dan menebal serta tidak memiliki vena sayap dan disebut elytra. Apabila istirahat, elytra seolah-olah terbagi menjadi dua (terbelah tepat di tengah-tengah bagian dorsal). Sayap belakang membranus dan jika sedang istirahat melipat di bawah sayap depan. Alat mulut bertipe penggigit-pengunyah, umumnya mandibula berkembang dengan baik. Pada beberapa jenis, khususnya dari suku Curculionidae alat mulutnya terbentuk pada moncong yang terbentuk di depan kepala. Metamorfose bertipe sempurna (holometabola) yang perkembangannya melalui stadia: telur-larva-kepompong (pupa)-dewasa (imago). Larva umumnya memiliki kaki thoracal (tipe oligopoda), namun ada beberapa jenis yang tidak berkaki (apoda).

\section{Ordo Lepidoptera (kupu/ngengat)}

Dari ordo ini, hanya stadium larva (ulat) saja yang berpotensi sebagai hama, namun beberapa diantaranya ada yang predator. Serangga dewasa umumnya sebagai pemakan/pengisap madu atau nektar. Sayap terdiri dari dua pasang, membranus dan tertutup oleh sisik-sisik yang berwarna-warni. Pada kepala dijumpai adanya alat mulut seranga bertipe pengisap, sedang larvanya memiliki tipe penggigit. Pada serangga dewasa, alat mulut berupa tabung yang disebut proboscis, palpus maxillaris dan mandibula biasanya mereduksi, tetapi palpus labialis berkembang sempurna. Metamorfose bertipe sempurna (Holometabola) yang perkembangannya melalui stadia: telur-larva-kepompong-dewasa. Larva bertipe polipoda, memiliki baik kaki thoracal maupun abdominal, sedang pupanya bertipe obtekta. 
Penelitian bertujuan untuk mengetahui jenis-jenis hama penting yang menyerang tanaman ubi jalar di lapang.

Manfaat penelitian adalah dengan diketahuinya jenis-jenis hama penting yang berasosiasi dengan tanaman ubi jalar maka penerapan pelaksanaan pengendalian akan lebih efektif dan efisien.

\section{METODE PENELITIAN}

Penelitian dilaksanakan pada dua tempat yaitu: 1) Di lapang areal pertanaman ubi jalar di Kabupaten Minahasa, Kabupaten Minahasa Utara dan Kota Tomohon yaitu Kelurahan Woloan Kecamatan Tomohon Selatan. 2) Di laboratorium Minat Hama dan penyakit Tumbuhan, Program Studi Agroekoteknologi, Fakultas Pertanian Unsrat Manado untuk melakukan tahapan identifikasi jenisjenis hama penting yang ditemukan pada tanaman ubi jalar. Lamanya penelitian diperkirakan selama 4 bulan sejak bulan Desember 2010 sampai Maret 2011.

Penelitian menggunakan metoda survey dengan pengambilan data atau sampel secara purposive sampling (pengambilan sampel secara sengaja). Objek penelitian diarahkan pada populasi tanaman yang telah ditanam oleh petani sesuai praktek usaha taninya. Kriteria tahapan perkembangan umur tanaman ubi jalar yang akan diperlukan dalam penelitian ini adalah sebagai berikut : 1) Umur 1 bulan sesudah tanam; 2) Umur 2 bulan sesudah tanaman; 3) Umur 3 bulan sesudah tanaman dan 4) Umur 4-5 bulan sesudah tanaman (saat panen). Sasaran pengamatan ditujukan pada bagian tanaman yang diduga terserang yaitu daun, batang, dan umbi tanaman ubi jalar. Indentifikasi organisme pengganggu akan dibatasi hanya pada serangga hama dan menyerang tanaman ubi jalar di lapang. Dari setiap perkembangan umur tanaman akan diambil sampel bagian tanaman (daun, batang dan umbi) masingmasing 10 contoh yang akan dimasukan dalam kantong plastik dan di beri label. Selain itu pula akan dilakukan pengamatan langsung terhadap serangga-serangga hama penting baik stadian larva, nimfa maupun dewasa. Bagi sampel tanaman yang diduga terinfestasi serangga maka stadia pradewasa seperti pada umbi, batang, dan daun akan dikoleksi untuk dipelihara lebih lanjut di laboratorium sedangkan untuk serangga yang aktif akan ditangkap menggunakan jaring serangga atau ditangkap langsung. Seluruh sampel yang diambil dari lapang akan dibawah ke laboratorium untuk diidentifikasi.

\section{HASIL DAN PEMBAHASAN}

\section{Hasil Penelitian \\ Tomohon, Kawangkoan dan Kakas}

Tabel 1. Jenis Hama dan Kerusakan pada Umur Tanaman 1 bulan Setelah Tanam

(Table 1. Types of pests and damage of plant at the age of 1 month after planting)

\begin{tabular}{|c|c|c|c|}
\hline No. & Ordo & Famili/Spesies & Kerusakan \\
\hline 1. & Hemiptera & Coreidae & $\begin{array}{l}\text { Nimfa menyerang bagian daun tanaman dan } \\
\text { membuat lubang }\end{array}$ \\
\hline 2. & Homoptera & Cicadelidae & Menyerang bagian daun dengan cara mengisap \\
\hline 3. & Lepidoptera & $\begin{array}{l}\text { Noctuidae } \\
\text { Spodoptera sp }\end{array}$ & Menyerang bagian daun dengan cara memotong \\
\hline
\end{tabular}

Tabel 2. Jenis Hama dan Kerusakan pada Umur Tanaman 2 Bulan Setelah Tanam (Table 2. Types of pests and damage of plant at the age of 2 months after planting)

\begin{tabular}{llll}
\hline No. & \multicolumn{1}{c}{ Ordo } & \multicolumn{1}{c}{ Famili/Spesies } & \multicolumn{1}{c}{ Kerusakan } \\
\hline 1. & Orthoptera & Acrididae & Nimfa menyerang bagian daun tanaman sehingga rusak \\
& & Valanga sp & \\
2. & Hemiptera & Coreidae & Menyerang bagian daun dengan cara mengisap \\
3. & Lepidoptera & $\begin{array}{l}\text { Noctuidae } \\
\text { Spodoptera sp }\end{array}$ & Menyerang bagian daun dengan cara memotong \\
& & $\begin{array}{l}\text { Pyralidae } \\
\text { Omphysa sp }\end{array}$ & Menyerang bagian batang dan umbi \\
& & & \\
\hline
\end{tabular}


Tabel 3. Jenis Hama dan Kerusakan pada Umur Tanaman 3 Bulan Setelah Tanam

(Table 3. Types of pests and damage of plant at the age of 3 months after planting)

\begin{tabular}{lrll}
\hline No. & \multicolumn{1}{c}{ Ordo } & \multicolumn{1}{c}{ Famili/Spesies } & \multicolumn{1}{c}{ Kerusakan } \\
\hline 1. & Orthoptera & $\begin{array}{l}\text { Gryllotalpidae } \\
\text { (Gryllotalpa sp) }\end{array}$ & $\begin{array}{l}\text { Serangga ini terlihat saat tanaman berumur } 3 \text { bulan dan } \\
\text { menyerang umbi dengan gejala adanya bekas-bekas } \\
\text { gigitan }\end{array}$ \\
2. & & $\begin{array}{l}\text { Acrididae } \\
\text { (Valanga sp) }\end{array}$ & $\begin{array}{l}\text { Menyerang bagian daun dengan cara membuat lubang } \\
\text { atau kerusakan dari pinggiran daun }\end{array}$ \\
3. & Coleoptera & $\begin{array}{l}\text { Curculionidae } \\
\text { (cylas formicarius })\end{array}$ & $\begin{array}{l}\text { Menyerang bagian umbi dan larva dapat ditemukan dalam } \\
\text { umbi. Lubang gerekan tertutup dengan kotoran berwarna } \\
\text { hijau dan berbau menyengat }\end{array}$ \\
& &
\end{tabular}

Tabel 4. Jenis Hama dan Keruskan pada umur Tanaman > 4 Bulan Setelah Tanam

(Table 4. Types of pests and damage of plant at the age of $>4$ months after planting)

\begin{tabular}{|c|c|c|c|}
\hline No. & Ordo & Famili/Spesies & Kerusakan \\
\hline 1. & Orthoptera & $\begin{array}{l}\text { Gryllotalpidae } \\
\text { (Gryllotalpa spp) } \\
\text { Acrididae } \\
\text { (Valanga sp ) }\end{array}$ & $\begin{array}{l}\text { Serangga ini terlihat saat tanaman berumur } 3 \text { bulan dan } \\
\text { menyerang umbi dengan gejala adanya bekas-bekas gigitan } \\
\text { Menyerang bagian daun dengan cara membuat lubang atau } \\
\text { kerusakan dari pinggiran daun }\end{array}$ \\
\hline 2. & Coleoptera & $\begin{array}{l}\text { Curculionidae } \\
\text { (Cylas formicarius ) }\end{array}$ & $\begin{array}{l}\text { Menyerang bagian umbi dan larva serta pupa dapat } \\
\text { ditemukan dalam umbi. Lubang gerekan tertutup dengan } \\
\text { kotoran berwarna hijau dan berbau menyengat. Serangan } \\
\text { hama ini umumnya terjadi ketika tanaman berumur } 4 \text { bulan } \\
\text { ke atas }\end{array}$ \\
\hline
\end{tabular}

\section{Minahasa Utara (Sukur dan Suwaan)}

Tabel 5. Jenis Hama dan kerusakan pada Umur Tanaman 1-4 Bulan Setelah Tanam

(Table 5. Types of pests and damage of plant at the age of 1-4 months after planting)

\begin{tabular}{|c|c|c|c|}
\hline No. & Ordo & Famili/Spesies & Kerusakan \\
\hline 1. & Orthoptera & $\begin{array}{l}\text { Acrididae } \\
\text { (Oxya sp) } \\
\text { Acrididae } \\
\text { (Valanga sp) }\end{array}$ & $\begin{array}{l}\text { Belalang kecil ini berwarna coklat dengan tubuh kecil dan } \\
\text { berantena pendek. Merusak daun tanaman hingga terlihat } \\
\text { sobek dengan torehan } \\
\text { Menyerang bagian daun dengan cara membuat lubang atau } \\
\text { kerusakan dari pinggiran daun }\end{array}$ \\
\hline 2. & Coleoptera & Coccinelidae & $\begin{array}{l}\text { Kumbang kecil berwana kuning dengan sepasang strip hitam di } \\
\text { bagian punggung. Daun yang diserang akan berlubang dgn } \\
\text { diameter } 0,5-1 \mathrm{~cm}\end{array}$ \\
\hline 3. & Coleoptera & $\begin{array}{l}\text { Curculionidae } \\
\text { (Cylas formicarius ) }\end{array}$ & $\begin{array}{l}\text { Menyerang bagian umbi dan larva serta pupa dapat ditemukan } \\
\text { dalam umbi. Lubang gerekan tertutup dengan kotoran berwarna } \\
\text { hijau dan berbau menyengat. Serangan hama ini umumnya } \\
\text { terjadi ketika tanaman/umbi berumur } 4 \text { bulan ke atas. } \\
\text { Prosentase serangan berkisar } 15-50 \text { persen dengan rata-rata } \\
35 \text { persen. Serangan hama ini sangat berpotensi menurunkan } \\
\text { nilai ekonomi sebab produksi menjadi rusak. }\end{array}$ \\
\hline 4. & Coleoptera & $\begin{array}{l}\text { Larva Dynastidae } \\
\text { Oryctes sp }\end{array}$ & $\begin{array}{l}\text { Larva kumbang memakan kulit umbi sehingga akan ditemukan } \\
\text { bagian permukaan kulit luka terkelupa }\end{array}$ \\
\hline 5. & Lepidoptera & $\begin{array}{l}\text { Noctuidae } \\
\text { Spodoptera sp }\end{array}$ & Menyerang bagian daun dengan cara memotong \\
\hline
\end{tabular}




\section{Pembahasan}

Hasil penelitian seperti pada Tabel 1-5 menunjukkan bahwa jenis-jenis hama penting yang teridentifikasi berdasarkan karakter morfologi dan sifat serangan serta kerusakannya dari wilayah Kota Tomohon dan Kabupaten Minahasa yaitu Kecamatan Kawangkoan dan Kakas terdapat lima ordo penting yaitu Orthoptera, Coleoptera, Lepidoptera, Hemiptera dan Homoptera. Kelima ordo tersebut menyerang tanaman ubi jalar sejak berumur satu bulan sampai lebih empat bulan sesudah tanam.Jenis hama penting pada umur tanaman 1 bulan setelah tanam terdapat 3 ordo yaitu ordo Hemiptera adalah kepik Coreidae perusak daun, ordo Homoptera adalah Cicadelidae perusak daun, dan ordo Lepidoptera adalah Larva perusak daun, Spodoptera sp. (Noctuidae) (lihat gambar 1).

Pada umur tanaman 2 bulan setelah tanaman terdapat 3 ordo yaitu ordo Orthoptera adalah perusak daun Valanga sp. (Acrididae),ordo Hemiptera yaitu kepik pengisap daun Coreidae, dan ordo Lepidoptera adalah Larva perusak daun, Spodoptera sp. (Noctuidae) dan Larva penggerek batang, Omphisa sp. (Pyralidae) (lihat gambar 2).

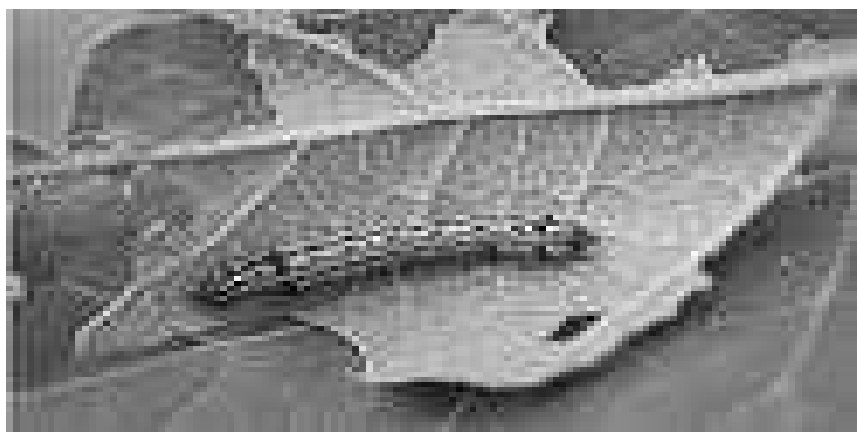

Gambar 1. Larva Spodoptera sp (Noctuidae)

(Figure 1. Larvae Spodoptera sp (Noctuidae)

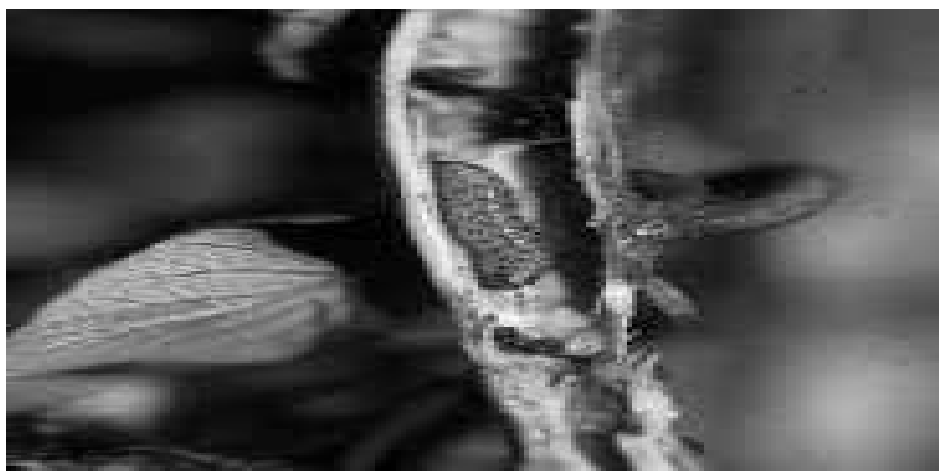

Gambar 2. Larva Omphisa sp (Pyralidae)

(Figure 2. Larvae Omphisa sp (Pyralidae)
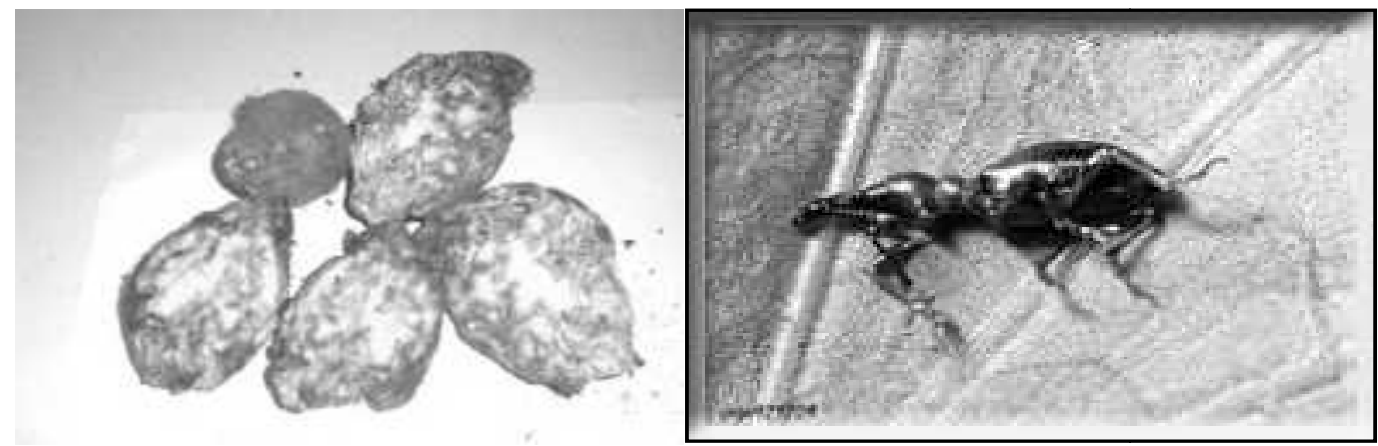

Gambar 3. Kiri : Umbi yang terserang; Kanan : Cylas formicarius dewasa (Figure 3. Left : The tubers area attacked, right : adult Cylas formicarius) 


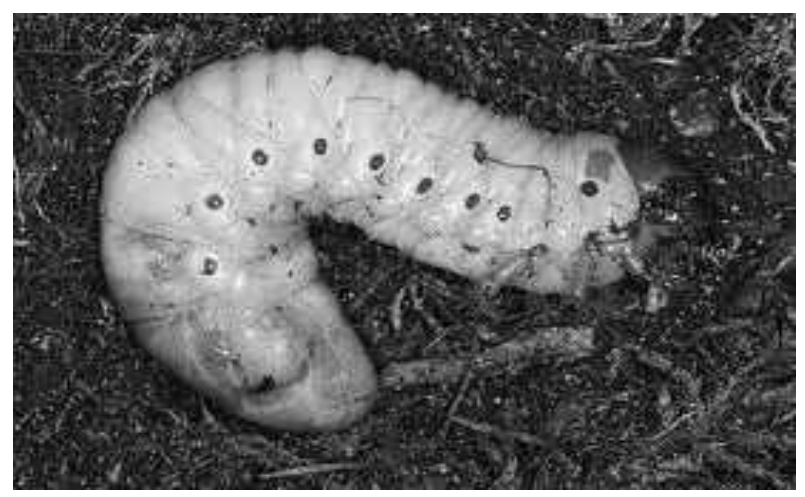

Gambar 4. Larva Oryctes sp

(Figure 4. Larvae Oryctes sp)

Pada umur tanaman 3 dan 4 bulan sesudah tanam terdapat dua ordo yang mendominasi dan berperan sebagai hama yaitu ordo Orthoptera adalah perusak umbi, Gryllotalpa sp. (Gryllotalpidae) dan perusak daun Valanga sp. (Acrididae) dan ordo Coleoptera adalah perusak umbi Cylas formicarius (Curculionidae) (gambar 3). Khusus untuk hasil pengamatan wilayah Kabupaten Minahasa Utara yakni Desa Sukur dan Suwaan yang dilakukan pada umur tanaman 1-4 bulan sesudah tanam terdapat 3 ordo penting yaitu ordo Orthoptera, Coleoptera dan Lepidoptera. Untuk ordo Orthoptera merupakan hama perusak daun yaitu belalang oxya sp. (Acrididae) dan Valanga sp. (Acrididae); ordo Coleoptera adalah kumbang perusak daun Coccinelidae, kumbang perusak umbi Oryctes sp. (Dynastidae) (lihat gambar 4) dan kumbang perusak umbi Cylas formicarius (Curculionidae) dan Ordo Lepidoptera adalah larva perusak daun Spodoptera sp. (Noctuidae).

\section{KESIMPULAN}

Jenis-jenis hama yang menyerang tanaman ubi jalar (I. batatas L.) sejak berumur 1-4 bulan sesudah tanaman di wilayah kabupaten Minahasa, Kota Tomohon dan Kabupaten Minahasa Utara terdiri dari 5 ordo yaitu ordo Orthoptera, Hemiptera, Homoptera, Lepidoptera, dan Coleoptera.

Kerusakan yang ditimbulkan pada bagian daun diserang oleh hama coreidae, Cicadelidae, Spodoptera sp. (Noctuidae), Valanga sp. (Acrididae), dan Oxya sp. (Acrididae); pada bagian batang adalah Omphisa sp. (Pyralidae); dan pada bagian umbi adalah Gryllotalpa sp. (Gryllotalpidae), Cylas formicarius (Curculionidae) dan Oryctes sp. (Dynastidae).

\section{DAFTAR PUSTAKA}

Anonim, 2009. http://www.scribd.com/doc/ 21400006/makalah-hama-ubi

Anonim, 2010. Teknologi Budidaya Ubi Jalar. Publikasi-Panduan/Petunjuk Teknis. http://sulsel.litbang.deptan.go.id/index.php ?option=com content\&view+articel\&id +13 3:teknologi-budidaya-ubi-jalar\&catid+48: panduanpetunjuk-teknis-leaflet\& Itemid $=53$

Duryatmo, S., 2010. Menanti Laba dari Satsumaino - Trubus. No. 384- Nopember 2001.

Kalshoven, L.G.E., 1981. Pest of Crops In Indonesia. PT. Ichtiar baru. Jakarta

Pracaya, 1993. Hama Penyakit Tanaman. Penebar Swadaya, Jakarta

Rodesa, 2008. Serangga Hama Pada tanaman Ubi Jalar Http://.www.Papua. Raksaworpress. $\mathrm{com} / .7$.

Rukmana, R., 1997. Ubi Jalar-Budidaya dan Pascapanen. Kanisius. Yogyakarta.

Sarwono, B., 2011. Cara Budi Daya yang Tepat, Efisien dan Ekonomis. Penebar. Jakarta. 
